\title{
Characterization of Some Commercial Soaps By X-Ray Diffraction
}

\author{
By Gopal S. Hattiangdi ${ }^{2}$
}

\begin{abstract}
The diffraction of X-rays by 29 commercial soaps was investigated. The patterns indicate that the soaps are crystalline, and the data have been used to identify the various phases in the solid soaps. The single long-spacing value obtained for the toilet, medicated, glycerin, coco, and washing soaps is indicative of the existence of a single crystal type in these soaps. The exhibition of two or three sets of long-spacing values by the shaving soaps is indicative of the presence in these soaps of two or three individual phases.

The moisture content of these soaps indicates that the toilet and medicated soaps are either hemihydrates or monohydrates; the coco soaps, dihydrates; and the shaving soaps, monohydrates.
\end{abstract}

\section{Introduction}

The purpose of this paper is to present X-ray diffraction data for numerous types of commercial soaps manufactured in India and in the United States, and to correlate these with data for pure single soaps with a view to obtaining information, insofar as possible, regarding the degree of crystallinity and phase nature of these systems. It is hoped ultimately to correlate these X-ray data with the physical-chemical properties of aqueous soap solutions and their washing (cleansing) action. Results pertaining to these latter properties and also some information relating to phase nature, as revealed by electron microscopy, are presented in RP1973 and RP1974 [23].

Soaps are the metal salts of the higher saturated and unsaturated fatty acids and of rosin acids; they are sometimes understood to include salts of naphthenic acids and of synthetic "fatty" acids. Only the alkali and ammonium soaps, and some

\footnotetext{
${ }^{1}$ Part of this work was conducted by the author in the Chemistry Department, University of Southern California, Los Angeles 7, Calif.

${ }^{2}$ Guest worker, Surface Chemistry Section.
}

organic-base salts like triethanolamine soaps, are freely soluble in water and therefore suitable as detergents in aqueous solution. In the case of the saturated fatty acids, the property of detergency of the corresponding soaps is limited to those containing at least 8 and not more than 22 carbon atoms.

Several workers $[2,4,6,12,13]^{3}$ have emphasized the importance of thermal and mechanical treatment given to pure sodium soaps, inasmuch as their transformation from one phase to another is readily achieved. Although the composition of the fatty stock used in the manufacture of soaps may vary from batch to batch, and certainly from manufacturer to manufacturer, it may be well to consider briefly the soap-boiling process so as to understand the extent and nature of mechanical and thermal treatment that a commercial soap receives.

Soap is obtained by saponification of fats or oils, the nature of the fatty stock largely determining the characteristics of the resultant soap. The

\footnotetext{
${ }^{3}$ Figures in brackets indicate the literature references at the end of this paper.
} 
soap-boiling process involves the fact that soaps are soluble in dilute aqueous solutions of electrolytes but become quite insoluble when the concentration of the electrolyte is increased. Consequently, after saponification of the fat or oil is completed, salt is added, which separates the system into the hydrous soap and "lye." The actual boiling process requires 2 to 8 days, depending upon the method used and the size of the charge, and involves at least five important stages or changes: (a) killing, (b) graining, (c) washing, (d) strengthening, and (3) fitting or pitching. Stages (a) and (b) of the soap-boiling process involve heating or "boiling" the charge with the aid of "open" or "closed" steam; stages (c) and (d) involve successive addition of water and vigorous boiling with open steam, whereas in stage (e) heating is discontinued, and slow separation of neat soap and "nigre" takes place. Nigre is a dark-colored layer intermediate between neat soap and lye and contains a high concentration of soap and salts. The soap thus obtained is vigorously boiled again with closed steam before it is permitted to settle, the latter process being carried out at approximately $65^{\circ} \mathrm{C}$ for 1 or 2 days, or even longer. The following four layers form in the final "settle": (1) a foamy top layer, called fob; (2) the main layer of soap, which, in the hot fluid condition, is known as neat soap; (3) nigre; and (4) a small amount. of lye, called pitch-water.

The important types of commercial soaps manufactured by the full-boiling process are milled soaps (toilet and shaving soaps), form-made soaps (household bar soaps and floating soaps), flake soaps (chipped and powdered soaps), and sprayed soaps (spray-dried and spray-crystallized soaps). Paste, cold-made coco, and liquid soaps are manufactured by the semiboiling process, the cold process, etc., in which the thermal and mechanical treatment given to the soaps is different from that in the full-boiling process.

Several years ago, McBain [14] presented an interpretation of the manufacture of soap by the boiling process on the basis of phase-rule diagrams derived by him and his collaborators. Since then, several workers have investigated systems of single and mixed soaps by employing different techniques. Investigations of binary and commercial-soap systems by X-ray diffraction revealed that commercial soaps crystallize as solid solutions with no evidence of fractional crystallization into the constituent single soaps [10]. Ferguson, et al. [12] have shown from X-ray diffraction studies that sodium soaps exist in four crystalline phases (alpha, beta, delta, and omega), which can be identified by the positions and intensities of the long and short spacings. When two or more phases are present simultaneously, however, the long spacing changes, but the short spacings retain their values and seem to be independent also of the fatty stock and moisture content. These characteristic short spacings are at 3.65 and $2.45 \mathrm{~A}$ for the alpha form, 2.75 $\mathrm{A}$ for beta, 3.55 and $2.85 \mathrm{~A}$ for delta, and 2.95 A for omega. Ferguson, et al., found that commercial milled soap containing 80 percent of tallow and 20 percent of coconut oil can be transformed into (a) the beta form by milling and plodding operations, (b) the omega form by heating in a sealed tube to $190^{\circ} \mathrm{F}$ and slow cooling, and (c) the delta form by reworking the original soap at a temperature around $50^{\circ}$ to $60^{\circ} \mathrm{F}$.

\section{Experimental Procedure}

\section{Materials Used}

Of the 29 soaps investigated, 9 were manufactured in the United States and 20 in India. All the soaps were purchased in the retail market in the form supplied to customers, the soaps manufactured in India being mailed to the author about a month before they were X-rayed.

Of the 9 soaps manufactured in the United States, 6 were popular brands of toilet soaps, 2 were coco soaps, and 1 was a "medicinal" soap. Of the 20 soaps manufactured in India, 6 were toilet soaps, 2 were glycerin soaps, 2 were "medicated" soaps, 4 were washing, or laundry, soaps, and 6 were shaving soaps.

The soaps used for X-ray investigation were in the "air-dry" state. Their moisture content was determined by drying them to constant weight in an air oven at $107^{\circ} \mathrm{C}$. The results are presented on a percentage basis in tables 1 to 4 . 


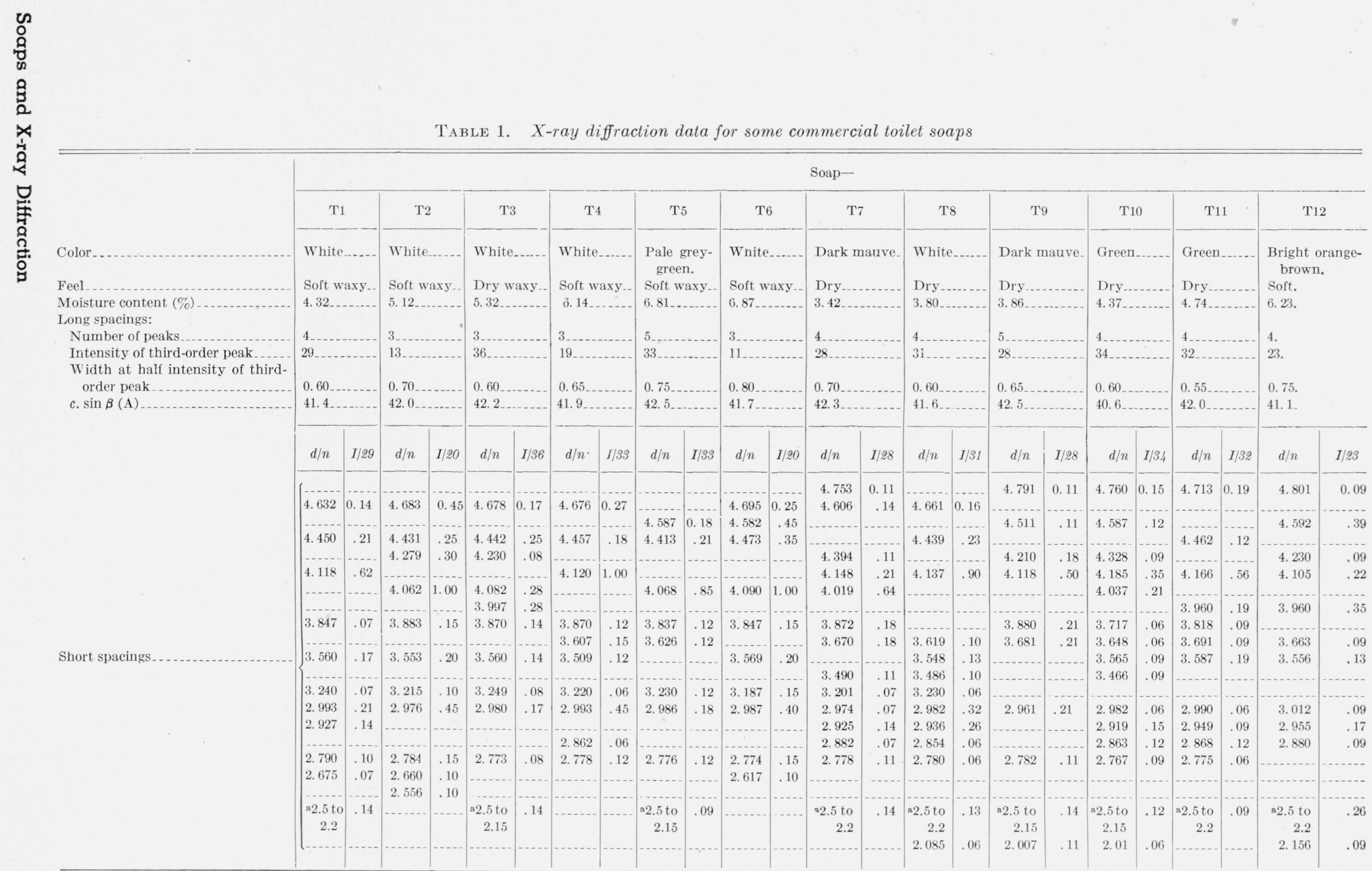

a Band. 
TABLe 2. X-ray diffraction data for some miscellaneous commercial toilet soaps

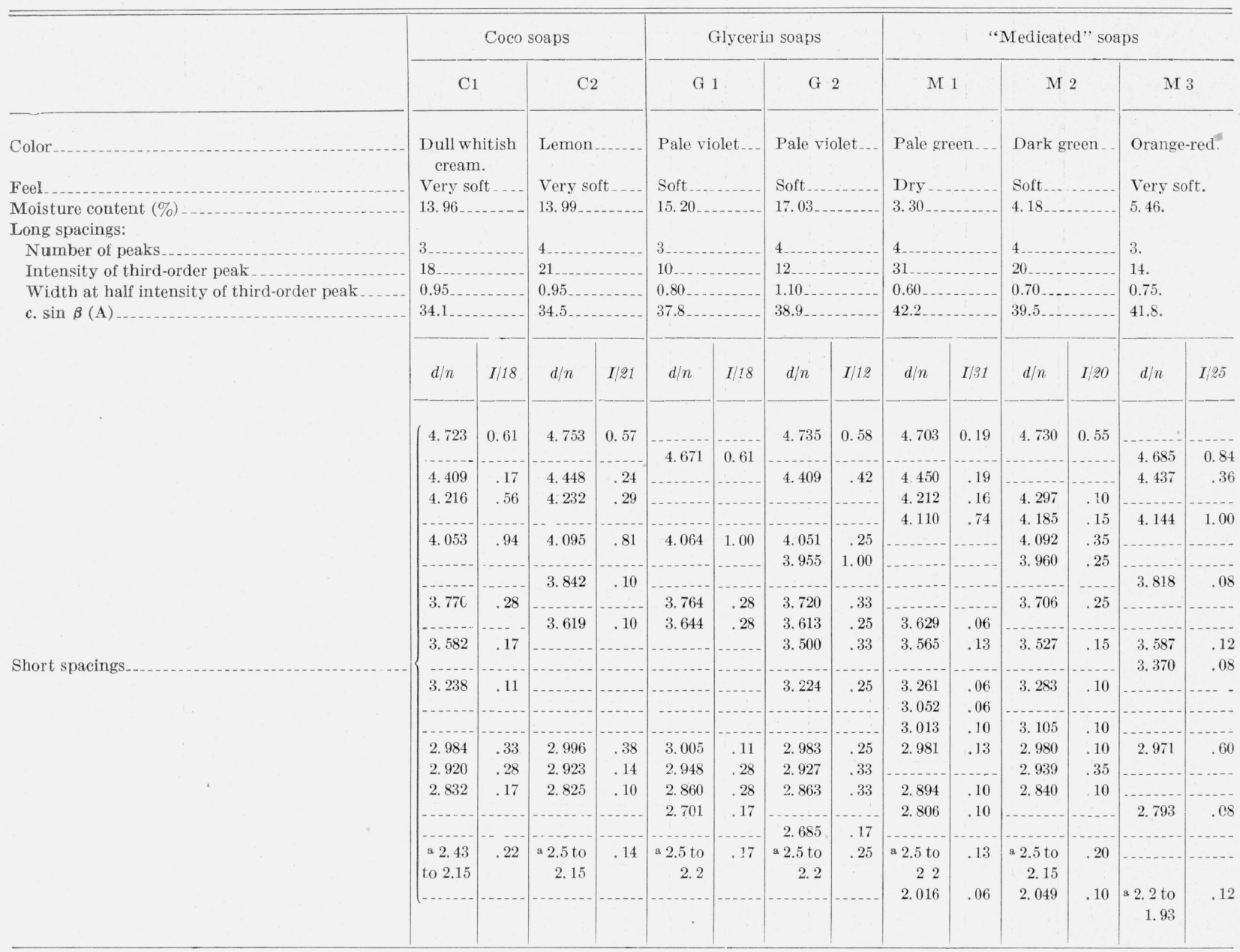

a Band. 


\begin{tabular}{|c|c|c|c|c|c|c|c|c|}
\hline & \multicolumn{8}{|c|}{ Soaps } \\
\hline & \multicolumn{2}{|c|}{ W1 } & \multicolumn{2}{|c|}{ W2 } & \multicolumn{2}{|c|}{ W3 } & \multicolumn{2}{|c|}{$\begin{array}{c}\text { W4 } \\
\text { (see page 339) }\end{array}$} \\
\hline $\begin{array}{l}\text { Color } \\
\text { Feel } \\
\text { Moisture content }(\%)\end{array}$ & \multicolumn{2}{|c|}{\begin{tabular}{|c|} 
Yellow ochre..... \\
Very soft. \\
11.46
\end{tabular}} & \multicolumn{2}{|c|}{\begin{tabular}{|l|} 
Pale yellow \\
Dry \\
13.39
\end{tabular}} & \multicolumn{2}{|c|}{$\begin{array}{l}\text { Pale yellow } \\
\text { Very dry } \\
14.60\end{array}$} & \multicolumn{2}{|c|}{$\begin{array}{l}\text { Pale yellow. } \\
\text { Soft. } \\
17.40 \text {. }\end{array}$} \\
\hline \multirow[b]{4}{*}{ Short spacings... } & $d / n$ & $I / 15$ & $d / n$ & $I / 7$ & $d / n$ & $I / 9$ & $d / n$ & $1 / 7$ \\
\hline & 4. 120 & .53 & 4. 064 & .86 & 4. 101 & .89 & 4. 069 & $\begin{array}{r}.29 \\
1.00\end{array}$ \\
\hline & 3.978 & .47 & 3. 882 & .29 & 3. 929 & .33 & 3.938 & 0.29 \\
\hline & 3.658 & .40 & 3. 673 . & .43 & 3.623 & .33 & 3.652 & .29 \\
\hline & 3,494 & .27 & 3.472 & .29 & 3.473 & .33 & 3.449 & .29 \\
\hline & 3.030 & .13 & 3.019 & .29 & 3. 098 & .33 & 3.016 & .29 \\
\hline \multirow{3}{*}{ - } & $\begin{array}{l}\text { 2. } 942 \\
\text { 2.862 }\end{array}$ & .42 & 2. 969 & $\begin{array}{l}1.00 \\
0.29\end{array}$ & 2. 962 & .56 & 2. 960 & .86 \\
\hline & & .20 & 2.907 & & $\begin{array}{l}2.671 \\
2.452\end{array}$ & $\begin{array}{l}.44 \\
.33\end{array}$ & 2.866 & .43 \\
\hline & $\begin{array}{l}\text { a } 2.5 \text { to } \\
\quad 2.2\end{array}$ & .27 & 2.337 & .29 & $\begin{array}{c}\text { a } 2.43 \text { to } \\
2.2\end{array}$ & .33 & $\begin{array}{c}\text { a } 2.43 \text { to } \\
2.2\end{array}$ & .29 \\
\hline
\end{tabular}

s Band. 
TABLE 4. X-ray diffraction data for some commercial shaving soaps

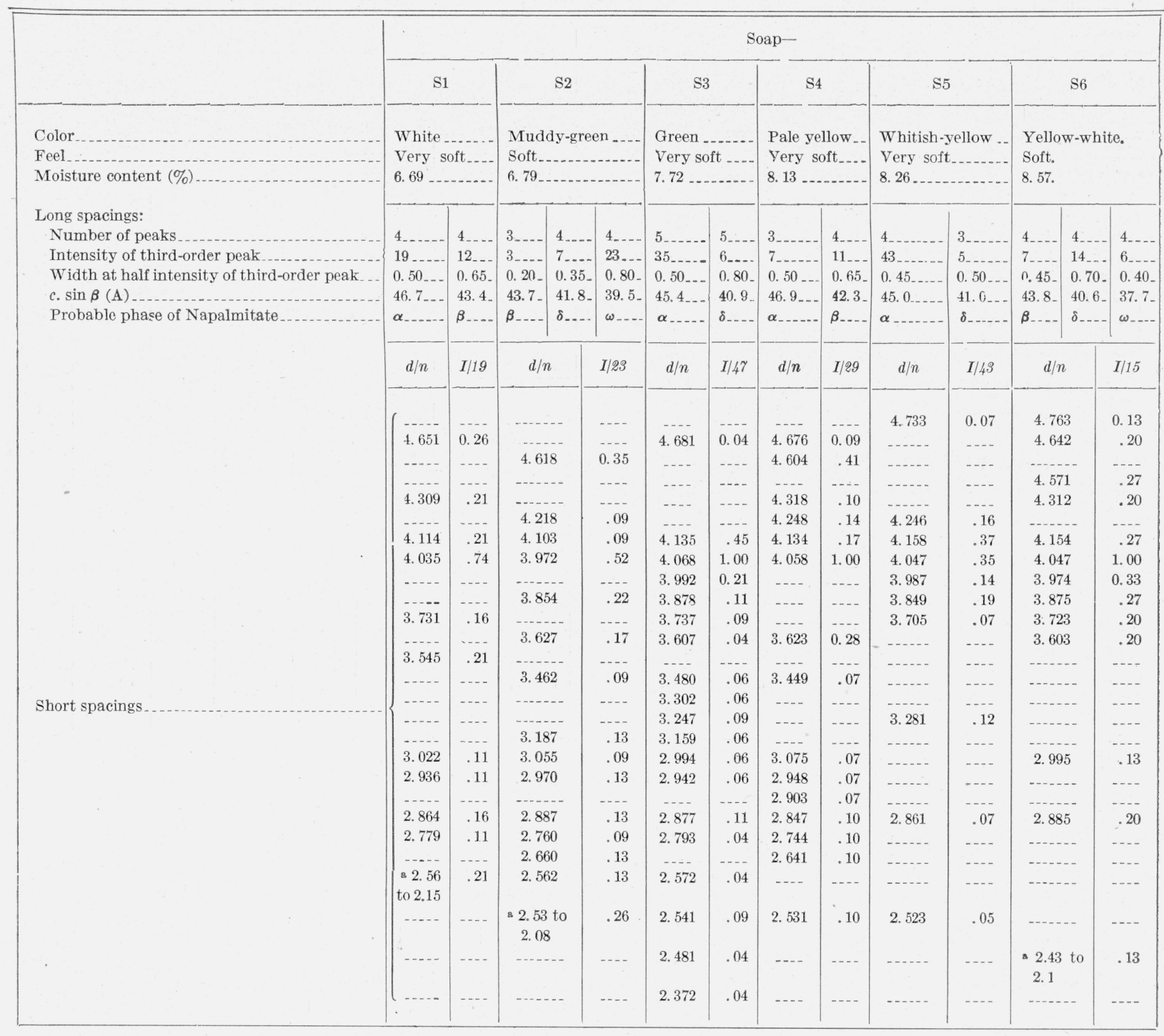

a Band.

\section{X-ray Diffraction Technique}

X-ray diffraction patterns were obtained by using a North American Philips Co. Geiger-Müller $\mathrm{X}$-ray spectrometer with $\mathrm{Cu} \mathrm{K} \alpha$ radiations, the intensity of the diffracted rays and the diffraction angle being recorded automatically on an electronic strip-chart recording potentiometer. Samples for X-ray examination were packed into a circular hole $\frac{5}{8} \mathrm{in}$. in diamater cut in a 1 - by 3 -in. microscope slide, and smoothed off with a glass plate. More elaborate procedural details are described elsewhere [21,22].

Bragg spacings $(d / n)$, corresponding to inter- planar distances of the crystal lattice, were calculated from the positions of the peaks in the curves according to the relation $n \lambda=2 d \sin \theta$, using the weighted average wavelength of $\mathrm{CuK} \alpha_{1}$ and $\mathrm{CuK} \alpha_{2}$ radiations from the copper X-ray target tube, namely, $\lambda=1.5418 \mathrm{~A}$. The weighted average was used because the positions of the centers rather than of the maxima of the peaks were determined. Measurements were made to $0.01^{\circ}$ in the value of the diffraction angle $2 \theta$. Values of $d / n$ calculated from the measurements were reproducible to 0.02 $\overline{\mathrm{A}}$ at large angles and $0.2 \mathrm{~A}$ at angles as small as $2 \theta=5^{\circ}$. 
The long spacings given in tables 1 to 4 represent the length $c . \sin \beta$ and were determined by averaging values calculated from the positions of peaks corresponding to the third and successive orders. Values were not calculated from the positions for the first and second order long-spacing peaks, because their positions cannot be determined accurately by the present experimental set-up. The intensities of the short spacing peaks are expressed as their amplitudes above the baseline divided by that of the most intense peak in the pattern, which is frequently the third order of the long spacing, or the short spacing around $4.1 \mathrm{~A}$. Relative intensities from line to line are directly comparable for a given soap pattern but are not comparable

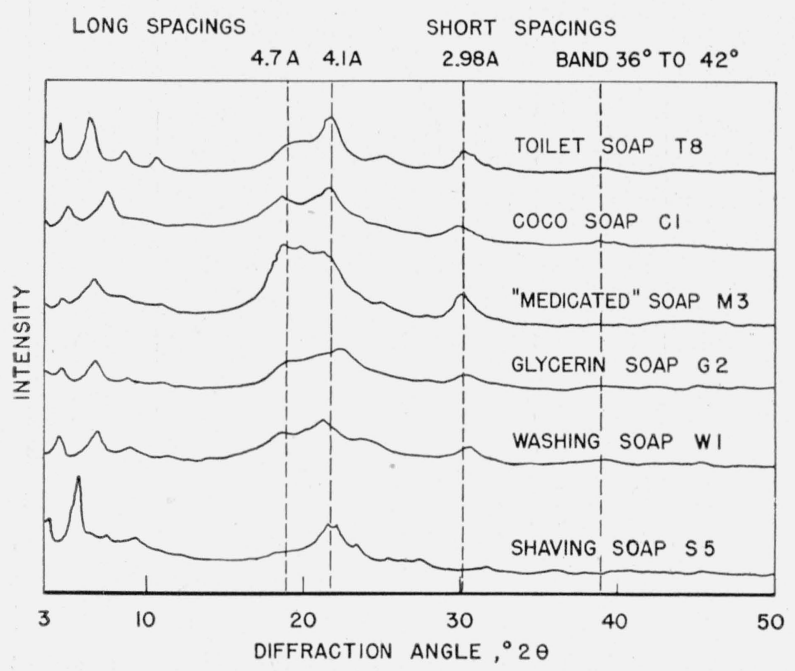

FIGURE 1. X-ray diffraction patterns of some commercial soaps

from soap to soap because of different reference intensities in different cases, as well as because of the difficulty of reproducing sample surface sufficiently closely to obtain reproducible values of absolute intensities.

Data for all the soaps, including the positions and relative intensities of the lines, bands, etc., are given in tables 1 to 4 . However, since the degree of crystallinity can best be seen in terms of the sharpness of the pattern, representative one-fifth reductions of the original curves of intensity versus diffraction angle are given for six soaps in figure 1. The choice of the soaps and the order of their presentation is purely arbitrary. Values of the width at half intensity of the third order longspacing peaks are also presented in tables 1 to 4 .

\section{Discussion}

\section{Appearance and Origin of the Diffraction Pattern}

Examination of a typical X-ray diffraction pattern, such as that for soap T8 in figure 1, shows that it consists of a series of sharp, fairly intense peaks between $2 \theta=3^{\circ}$ and $10^{\circ}$, a second group of sharp, intense peaks between $20^{\circ}$ and $30^{\circ}$, and a number of fainter peaks (not very evident on the reduced drawings) spread over the whole range.

The peaks at small angles arise from diffraction of X-rays by planes of atoms whose separation is proportional to the length of the soap molecule, $c \cdot \sin \beta$. In all the soaps investigated, successive orders of this distance, $d / 3, d / 4$, etc., appear as peaks in the diffraction pattern; $d / 1$, and $d / 2$ generally occur at such small angles that values obtained with the present instrumental set-up are not accurate. The relative intensities of the several orders of the long spacing vary from soap to soap, being a function both of the crystal type and the scattering power of the various atoms for X-rays.

The peaks in the intermediate angle range arise from the diffraction of X-rays from planes of atoms separated by much smaller distances than those described above and are referred to as short spacings. The numerical values give distances between planes in the crystal lattice and can be related directly to the distances between the mole-cules by making assumptions about the crystal type.

Individual peaks vary considerably in their angular width at half maximum intensity. A good example is to be seen in comparing the peak at around 4.1 A for soaps T8 and G2 in figure 1. A wide peak, such as that for the latter soap, may be referred to as a "halo". The occurrence of halos in these patterns is indicative either of a molecular arrangement less orderly than that of a three-dimensional crystal, a very small size of crystallites, or small spatial extent of crystallized regions within a different phase.

\section{Toilet Soaps}

The toilet soaps are all characterized, by relatively low moistuึre content, varying from 3.42 to 6.87 percent. The theoretical hemihydrate composition for sodium stearate, sodium palmitate, 
and sodium oleate is $2.86,3.12$, and 2.87 percent of $\mathrm{H}_{2} \mathrm{O}$, respectively. Toilet soaps commonly utilize a stock consisting of two-thirds tallow or highgrade fat and one-third coconut oil or other kernel oil, and thus have a high palmitate content. It seems reasonable therefore to assume that all the toilet soaps investigated here are hydrated to an extent of about 0.5 to 1 mole of $\mathrm{H}_{2} \mathrm{O}$ per mole of soap.

For pure single soaps, each crystal modification has its own field of stability with respect to hydration or moisture. Its composition and temperature range, and the possible equilibria with other soap phases, constitute the phase diagram for the particular soap-water system. On the contrary, commercial soaps are convenient mixtures made from fats and oils containing both saturated and unsaturated components of varying chain lengths, and thus have complex phase diagrams. It is interesting, however, to test the applicability of Ferguson's hypothesis [12] regarding the absence of the alpha phase and the presence of only three phases (beta, omega, and delta) in commercial soaps to the present data.

The long-spacing value for the toilet soaps varies from $40.6 \mathrm{~A}$ for T10 to $42.5 \mathrm{~A}$ for $\mathrm{T} 5$ and T9; the mean average for the soaps manufactured in India is $41.7 \mathrm{~A}$, and for those manufactured in the United States is $42 \mathrm{~A}$. The long-spacing values for pure single sodium soaps reported in the literature are presented in table 5, in which the nomenclature used to designate the various phases is the same as that adopted by Ferguson, et al. [12]. Accordingly, Buerger's [6] kappa and eta phases and McBain's [7, 8] gamma correspond to Ferguson's omega, and Buerger's epsilon and zeta correspond to Ferguson's beta.

It is seen that the closest agreement of the longspacing values for the toilet soaps seems to be with that for beta sodium palmitate, the values for sodium stearate and sodium oleate being rather high, and those for sodium laurate and sodium myristate being low. It is interesting to confirm the presence of beta sodium palmitate in these toilet soaps by comparing their short-spacing values with those reported by Thiessen and Ehrlich [18], Ferguson, et al. [12], and McBain, et al. [15]. It will be evident from table 5 that the agreement among the four sets of data is fair: the strong lines around $4.3,3.9,3.2,3.1$, and $2.7 \mathrm{~A}$ seem to match pretty well, and so do a number of other weaker lines. (The italicized values in this table are for the very strong, strong, and medium lines reported by the authors; the other lines are weak or very weak.) There also seems to be good agreement between these values for beta sodium palmitate and the short spacings obtained for the toilet soaps. It should be noted that the rather prominent "halo" around 2.95 A for the toilet soaps is characteristic of sodium oleate [20]. The halo from $36^{\circ}$ to $42^{\circ}$ in $2 \theta$ (centering around $2.4 \mathrm{~A}$ ) seems to be more characteristic of sodium oleate than of sodium palmitate [20].

\section{TABLE 5. Short spacings for beta sodium palmitate}

\begin{tabular}{|c|c|c|c|c|c|}
\hline $\begin{array}{c}\text { Thiessen } \\
\text { and } \\
\text { Ehrlich } \\
{[18]}\end{array}$ & $\begin{array}{l}\text { Ferguson, } \\
\text { et al. [12] }\end{array}$ & $\begin{array}{l}\text { McBain } \\
\text { et al. [15] }\end{array}$ & $\begin{array}{c}\text { Thiessen } \\
\text { and } \\
\text { Ehrlich } \\
{[18]}\end{array}$ & $\begin{array}{l}\text { Ferguson, } \\
\text { et al. [12] }\end{array}$ & $\begin{array}{l}\text { MeBain } \\
\text { et al. [15] }\end{array}$ \\
\hline \multirow[t]{3}{*}{$A$} & \multirow[t]{3}{*}{$A$} & $A$ & \multirow[t]{3}{*}{$A$} & $A$ & $A$ \\
\hline & & 4.43 & & 3. 19 & 3.10 \\
\hline & & 4.38 & & 2. 80 & 2. 81 \\
\hline \multirow[t]{3}{*}{4.28} & \multirow[t]{3}{*}{4.28} & 4. 26 & \multirow[t]{9}{*}{ 2. $\gamma_{6}$} & & 2.73 \\
\hline & & 4. 18 & & 2. 62 & 2. 64 \\
\hline & & 3. 99 & & 2. 48 & 2. 50 \\
\hline 3.88 & 3.85 & 3.90 & & 2. 35 & 2. 36 \\
\hline & & 3. 70 & & & 2.23 \\
\hline \multirow{4}{*}{3.19} & \multirow{4}{*}{3.48} & 3.64 & & & 2. 15 \\
\hline & & 3.49 & & & 2. 11 \\
\hline & & 3.19 & & & 1.95 \\
\hline & & 3. 18 & & 1. 78 & 1. $7 \gamma$ \\
\hline
\end{tabular}

In commercial soaps of low moisture content, simple cooling of neat soap produces the omega phase, which, in many cases, can be transformed into the beta phase by agitation at temperatures where the beta form is stable. The beta crystals are rapidly soluble and form lather easily, and thus have a direct and significant involvement in commercial soaps.

\section{Coco, Glycerin, and "Medicated" Soaps}

Both of the coco soaps investigated have an almost identical moisture content, namely, 13.96 and 13.99 percent, corresponding to about 2 moles of water per mole of soap. Their X-ray diffraction patterns are also identical in respect to the position, number, intensity, and sharpness of both the long- and short-spacing peaks. Both these soaps are reported by their manufacturers to have been made from pure coconut oil: the small long-spacing value of $34 \mathrm{~A}$ confirms the high laurate-myristate content to be expected from this oil stock; the main short spacings also agree reasonably well 
with the values reported by McBain, et al. [1] for sodium laurate.

The glycerin soaps have the highest moisture content among these soaps. Soap G2 has a moisture content of 17.03 percent and a long-spacing value of $38.9 \mathrm{~A}$, which is about $1 \mathrm{~A}$ longer than that for G1 (37.8 A), whose moisture content is 15.2 percent. These values of the long spacing are substantially lower than those for Pear's soap [17]. The long-spacing value for both G1 and G2 does not correspond to that for any single pure sodium soap, and it is therefore presumed that these are tallow-rosin soaps of rather indefinite fatty acid composition. The agreement between the short-spacing values for these two soaps and that for Pear's soap is relatively good. The glycerol halo, which should normally occur around 4.3 A [17], is not reported for both G1 and G2, because it is not clearly resolved; it probably is present, but the relatively high intensity of the closely situated peaks at 4.6 to $4.7 \mathrm{~A}$ and at 3.96 to $4.06 \mathrm{~A}$ evidently smears the glycerol halo.

The medicated soaps have a relatively low moisture content, corresponding to 0.5 mole of $\mathrm{H}_{2} \mathrm{O}$ per mole of soap. The values of the long spacing for all the three soaps lie close to that for beta sodium palmitate and, like the toilet soaps, many of the strong short spacings correspond to those for beta sodium palmitate and a few to those for sodium oleate. The general nature and characteristics of the X-ray diffraction patterns for these soaps are similar to those for the toilet soaps. It seems therefore that the incorporation of medicative materials does not alter the crystal habit of the soap molecule, although their presence seems to soften the "feel" of the products.

The single long-spacing value obtained for both the toilet and the medicated soaps is indicative of a single-crystal type rather than a mixture of individual components, which would exhibit several sets of long spacings.

\section{Washing Soaps}

Washing soap bars are characterized by high moisture content of the order of 11 to 17 percent, and a value of $c \cdot \sin \beta$ which ranges from 33.1 to 37.8 A. One of these soaps (W4 special washing soap) exhibits two distinct sets of long-spacing peaks corresponding to values of 34.3 and $41.3 \mathrm{~A}$. These soaps are evidently derived from tallow acids of rather indefinite and variable fatty acid composition, and the values of $c \cdot \sin \beta$ therefore do not correspond with those for any single pure soap of the acetic series.

There is good general agreement between the positions, relative intensities, and half-widths of peaks in the region of the short spacings for the washing soaps considered together. Since lines corresponding to $2.75,2.85$, and $3.55 \mathrm{~A}$ are missing in all the patterns, one is inclined to predict from Ferguson's phase-identification scheme [12] that the beta and delta phases are not present. On the contrary, lines corresponding to $2.45,3.65$, and $2.95 \mathrm{~A}$ are present; although it seems most unlikely that the alpha phase is present in these form-made washing soaps, the chances are that the omega phase is present to a predominating extent and contributes these above-mentioned lines.

The omega phase is believed to occur in commercial-framed and in most milled soaps, the proportion present depending on temperature, moisture, stock composition, and other processing conditions. This phase is obtained ordinarily by rapid chilling of neat soap without agitation, and always tends to form when low-moisture soaps of usual formulas are slow-cooled from the molten condition. In general, formation of the omega phase is favored by higher temperatures, lower moisture content, and low molecular weights. In commercial sodium oleate, it is perhaps the only stable form under most conditions [12].

\section{Shaving Soaps}

All of the six soaps investigated were in stick form and had a moisture content ranging from 6.7 to 8.6 percent, which is equivalent to about 1 mole of water per mole of soap. Four of these soaps had two separate sets of long-spacing peaks each, and two soaps, S2 and S6, exhibited three different sets. The lowest value of $c \cdot \sin \beta$ among these was $37.7 \mathrm{~A}$, and the longest was $46.9 \mathrm{~A}$. The most intense short spacing is around $4.0 \mathrm{~A}$ for each soap, and relatively weaker lines are present up to about $2.4 \mathrm{~A}$.

Shaving soaps are manufactured usually by the soap boiler's full-boiling process and are milled soaps. On the basis of the long-spacing values for sodium palmitate given in table 6 , it seems that the shaving soaps are mixtures of two or more phases of this soap. The probable phases in each soap are given in table 4 . The persistent exhibition of a long-spacing value corresponding approximately 
to that of alpha sodium palmitate is rather surprising, since this phase, unlike beta, omega, and delta, is rarely encountered in the usual commercial soaps. The alpha phase is usually the starting point for the formation of the other phases, however, and its presence in the shaving soaps is indicative of incomplete transformation to the other three phases. Transformation of the alpha form to the beta form is achieved by removal of water either by heating to about $52^{\circ} \mathrm{C}$ in an open or closed tube, by evacuation at room temperature, or by grinding at room temperature [4]. Also, water can be incorporated with the omega form to produce beta, and water can be driven off from beta to reduce it to omega. The formation of the delta phase is favored by high molecular weights, low soap content, and low temperatures. It is obtained in sodium palmitate by quenching nigre and in sodium stearate by ordinary cooling. Delta is also formed spontaneously at room temperature in 50 percent aqueous mixtures of alpha, beta, and omega palmitates. In addition, extrusion of sodium palmitate of high moisture content at and somewhat above room temperature converts the beta to the delta phase [12].

TABLE 6. Literature values of long spacing c.sin $\beta$, for sodium soaps

\begin{tabular}{|c|c|c|c|c|}
\hline \multirow{2}{*}{ Soap } & \multicolumn{4}{|c|}{ Phase } \\
\hline & Alpha & Beta & Omega & Delta \\
\hline Na-Laurate & & & $\left\{\begin{array}{l}31.5[12] \ldots \\
31.8[1] \ldots\end{array}\right.$ & \\
\hline Na-Myristate & & & $\left\{\begin{array}{l}36.0[10] \\
36 .\end{array}\right.$ & 36.5 [12] \\
\hline Na-Palmitate. & $\left\{\begin{array}{l}45.7[3] \ldots \\
46.6[12]\end{array}\right.$ & $\begin{array}{l}41.9[15]- \\
42.1[12]- \\
42.3[11]-\end{array}$ & $\begin{array}{l}39.6[12] \ldots \\
40.2[10] \ldots\end{array}$ & 10.6 [12] \\
\hline Na-Stearate_.. & $\left\{\begin{array}{l}51.4[12] \\
51.8[3] \\
51.9[16] \\
52.7[16]\end{array}\right.$ & $\begin{array}{l}45.8[12]- \\
46.2[16]- \\
46.3[19]- \\
46.5[16]-\end{array}$ & $\begin{array}{l}44.1[16] \ldots \\
44.4[12] \ldots \\
44.6[7,8] . \\
44.9[9,10] \\
45.0[16] \\
45.6[15] .\end{array}$ & 45.0 [12] \\
\hline Na-Oleate... & & & 44.9 [20] & 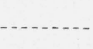 \\
\hline
\end{tabular}

6. Particle Size, Degree of Crystallinity, and Crystal Form

A crystalline soap, well developed in three dimensions, exhibits a sharp, rather intense long spacing and several short spacings that are well defined and that lead to sharp peaks in the X-ray diffraction pattern. Symmetry of the crystal lattice in certain cases may reduce the number of short spacings, but the spacings remain sharp and fairly intense. Several sharp short-spacing peaks combine to give a broad peak of a sort referred to as a halo, but when this occurs, it is usually found that this peak is more asymmetric than the halos obtained for liquids and for lesscrystalline arrangements.

The decrease in the degree of regularity may take place along one dimension at a time. If the regularity along the $c$-axis falls off, the long spacing decreases in intensity to the point of disappearance. If the decrease in regularity occurs along the other axes of the crystal arrangement, the long spacing remains relatively intense, but the number of the sharp short spacings decreases. In the extreme case, random orientation of the chains within sharply defined layers leads to sharp long spacings plus a liquid like halo (broad and nearly symmetrical) centered at an angle corresponding to the average separation of the hydrocarbon chains within the layers.

Different crystal forms are characterized by different unit cells, the most easily observed characteristic being perhaps the value of the long spacing, $c \cdot \sin \beta$, from which the angle of tilt, $\beta$, can be evaluated. The short spacings obtained for any arrangement of ions are not so easily correlated with structure. However, it might be that the translations along the $a$ - and $b$-axes of the unit cell should essentially be the spacings obtained, except for their absence due to extinctions corresponding to symmetry properties of the given crystal.

A decrease in the intensity of the different maxima, but with no change in the sharpness or number of the peaks, may be interpreted as being caused by dilution or by a decrease in the size of the crystalline particles present. An increase in the half-widths of ordinarily sharp peaks, but with no change in their intensity or number, is usually caused by the transformation of an orderly crystal form into a relatively disorganized liquidcrystalline form. A decrease in the number of lines with no change in the intensity, or sharpness, of the peaks may be interpreted as being due to the transformation of the material from one phase state to another. 


\section{Summary}

1. The diffraction of X-rays by 29 commercial soaps, including toilet, glycerin, medicated, coco, washing (laundry), and shaving soaps, was investigated. The degree of sharpness of the longand short-spacing peaks for the various soap patterns, including those for the glycerin soaps, indicates that the soaps are crystalline.

2. On the basis of their moisture content, the toilet and medicated soaps were found to be either hemihydrates or monohydrates, the coco soaps dihydrates, and the shaving soaps monohydrates.

3. The X-ray diffraction data have been used to identify the various phases present in the solid soaps. The values of the long and short spacings for the toilet and medicated soaps seem to indicate that these soaps consist essentially of beta sodium palmitate and to a smaller extent of omega sodium oleate. The glycerin soaps are evidently tallowrosin soaps of rather indefinite composition; they are not amorphous or undercooled liquids but contain very fine crystalline material. The coco soaps have a high laurate-myristate content of the omega phase. The washing (laundry) soaps exhibit long spacings that do not correspond to values for any single pure sodium soap, but their short spacings indicate the presence of theomega phase. The shaving soaps are characterized by the existence of two or more individual phases, probably of sodium palmitate, as evidenced by the presence in the X-ray diffraction patterns of two or more distinct sets of long-spacing lines.

The author is very grateful to Robert D. Vold, University of Southern California, Los Angeles, Calif., for use of the X-ray spectrometer and for general discussions on the interpretation of soap phases.

\section{References}

[1] O. E. A. Bolduan, J. W. McBain, and S. Ross, J. Phys. Chem. 47, 528 (1943).

[2] M. J. Buerger, Proc. Nat. Acad. Sci. 28, 529 (1942).

[3] M. J. Buerger, Am. Mineral. 30, 551 (1945).

[4] M. J. Buerger, L. B. Smith, A. DeBretteville, Jr., and F. V. Ryer, Proc. Nat. Acad. Sci. 28, 526 (1942).

[5] M. J. Buerger, L. B. Smith, and F. V. Ryer, J. Am. Oil Chem. Soc. 24, 193 (1947).

[6] M. J. Buerger, L. B. Smith, F. V. Ryer, and J. E. Spike, Jr., Proc. Nat. Acad. Sci. 31, 226 (1945).

[7] A. DeBretteville, Jr. and J. W. McBain, Science 96, 470 (1942).

[8] A. DeBretteville, Jr. and J. W. McBain, J. Chem. Phys. 11, 426 (1943).

[9] R. H. Ferguson, Oil \& Soap 21, 6 (1944).

[10] R. H. Ferguson and H. Nordsieck, Ind. Eng. Chem. 36, 748 (1944).

[11] R. H. Ferguson, F. B. Rosevear, and H. Nordsieck, J. Am. Chem. Soc. 69, 141 (1947).

[12] R. H. Ferguson, F. B. Rosevear, and R. C. Stillman, Ind. Eng. Chem. 35, 1005 (1943).

[13] K. W. Gardiner, M. J. Buerger, and L. B. Smith, J. Phys. Chem. 49, 417 (1945).

[14] J. W. McBain, third report on colloid chemistry and its general and industrial applications (Br. Assn. Adv. Sci.) p. 2 to 31 (1920); also numerous papers in J. Chem. Soc., J. Am. Chem. Soc., and Ind. Eng. Chem.

[15] J. W. MeBain, O. E. A. Bolduan, and S. Ross, J. Am. Chem. Soc. 65, 1873 (1943).

[16] J. W. McBain, A. DeBretteville, Jr., and S. Ross, J. Chem. Phys. 11, 179 (1943).

[17] J. W. McBain, and S. Ross, Oil \& Soap 21, 97 (1944); J. Am. Chem. Soc. 68, 296, 547 (1946).

[18] P. A. Thiessen and E. Ehrlich, Z. physik. Chem. 165A, 464 (1933).

[19] P. A. Thiessen and J. Stauff, Z. physik. Chem. 176A, 397 (1936).

[20] R. D. Vold and R. Clemens, private communication.

[21] R. D. Vold, J. D. Grandine, II, and M. J. Vold, J. Coll. Sci. 3, 339 (1948).

[22] R. D. Vold and G. S. Hattiangdi, Ind. \& Eng. Chem. Publication pending.

[23] G. Hattiangdi and M. Swerdlow, J. Research NBS 42, 343 (1949) RP1973; G. Hattiangdi, W. W. Walton, and J. I. Hoffman, J. Research NBS 42, 361 (1949) RP1974.

Washington, December 10, 1948. 